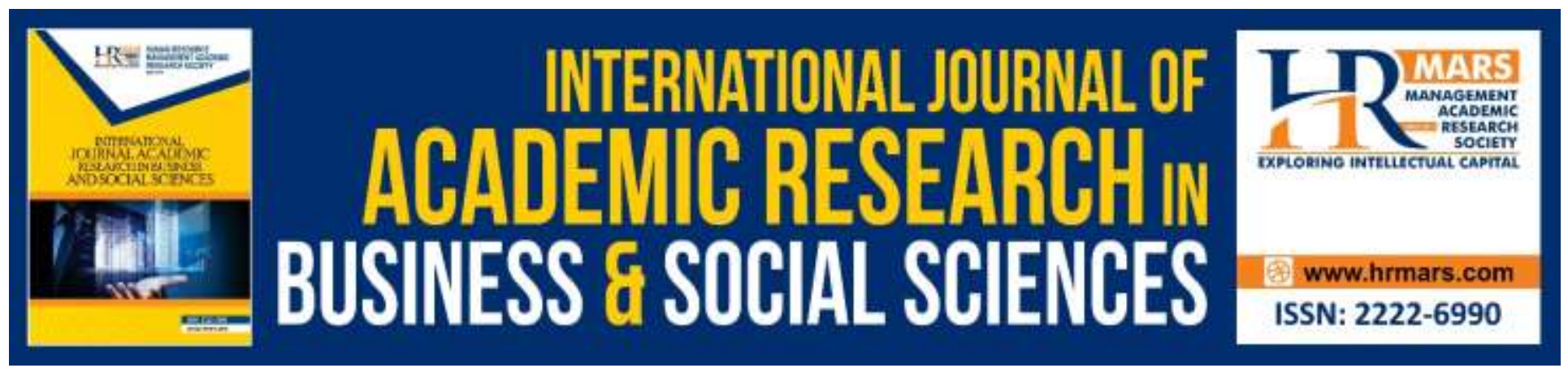

\title{
The Impact of Loyalty Value on Purchase Intention: Comparative Analysis of Healthy Food and Unhealthy Food Advertisements in Sri Lanka
}

\author{
D.M.N.I. Dissanayake, N.T. Seneviratne, L.A.D.S. Hansasara, L.D.N. Perera, \\ N.A. Jayasuriya
}

To Link this Article: http://dx.doi.org/10.6007/IJARBSS/v10-i5/7199

DOI:10.6007/IJARBSS/v10-i5/7199

Received: 10 March 2020, Revised: 12 April 2020, Accepted: 25 April 2020

Published Online: 14 May 2020

In-Text Citation: (Dissanayake et al., 2020)

To Cite this Article: Dissanayake, D. M. N. I., Seneviratne, N. T., Hansasara, L. A. D. S., Perera, L. D. N., \& Jayasuriya, N. A. (2020). The Impact of Loyalty Value on Purchase Intention: Comparative Analysis of Healthy Food and Unhealthy Food Advertisements in Sri Lanka. International Journal of Academic Research in Business and Social Sciences, 10(5), 312-321.

Copyright: (c) 2020 The Author(s)

Published by Human Resource Management Academic Research Society (www.hrmars.com)

This article is published under the Creative Commons Attribution (CC BY 4.0) license. Anyone may reproduce, distribute, translate and create derivative works of this article (for both commercial and non-commercial purposes), subject to full attribution to the original publication and authors. The full terms of this license may be seen at: http://creativecommons.org/licences/by/4.0/legalcode

Vol. 10, No. 5, 2020, Pg. 312 - 321

Full Terms \& Conditions of access and use can be found at http://hrmars.com/index.php/pages/detail/publication-ethics 


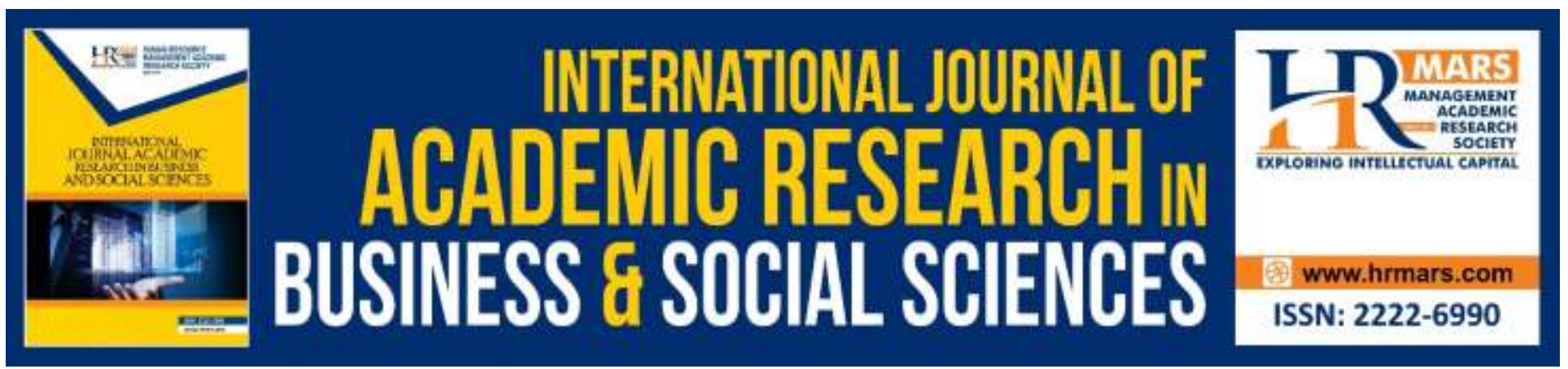

\title{
The Impact of Loyalty Value on Purchase Intention: Comparative Analysis of Healthy Food and Unhealthy Food Advertisements in Sri Lanka
}

\author{
D.M.N.I. Dissanayake ${ }^{1}$, N.T. Seneviratne ${ }^{2}$, L.A.D.S. Hansasara ${ }^{3}$, \\ L.D.N. Perera ${ }^{4}$, N.A. Jayasuriya ${ }^{5}$ \\ 1, 2, 3, 4 Undergraduate, SLIIT, Business School, SLIIT Malabe, Sri Lanka, ${ }^{5}$ Senior Lecturer, SLIIT, \\ Business School, SLIIT Malabe, Sri Lanka. \\ Email: navodithamari@gmail.com,nidissa9583@gmail.com, hansasara96@gmail.com, \\ dulangaperera00@gmail.com,nisha.j@sliit.lk.
}

\begin{abstract}
The purpose of the study is to seek the impact of loyalty on purchase intention of consumers with regard to healthy and unhealthy food advertisements in Sri Lanka. After referring to various past researches it has been identified that loyalty is one of the most influential factors in determining the purchase intention of consumers. However, when referring to past researches it has been evident that there is a lack of knowledge in the area of healthy and unhealthy food advertisements particularly in Sri Lankan context. Due to the shortfall of literature the present study concentrated on exploring the impact of loyalty towards the purchase intention of Sri Lankan consumers. Therefore, the objectives of the study were primarily achieved by analysing the data gathered via a selfadministered questionnaire that was distributed among 384 Sri Lankan consumers. Convenient sampling was the sampling method that was utilized and analytical techniques such as correlation and regression were applied. The present study indicated that loyalty has a positive impact towards purchase intention of Sri Lankan consumers when it comes to both healthy and unhealthy food advertisements. When it comes to the knowledge implications, the study is significant as it identified that that there is a strong correlation existing between the loyalty and purchase intention. It has also been apparent that brand loyalty is created through a past positive experience that a consumer has with a particular food brand.
\end{abstract}

Keywords: Advertisements, Health, Loyalty, Purchase Intention, Food.

\section{Introduction}

In Sri Lanka, unhealthy food advertisements are exceedingly successful and highly influential for consumer purchase intention, compared to healthy food advertisements. This has largely resulted in Sri Lankans consuming a greater proportion of unhealthy food than healthy food. The population of 
Sri Lanka is likely to inadvertently take note of these advertisements and tend to change their lifestyle and food consumption patterns (Muiz, 2015).

The dietary patterns of humans specially children and young adults are heavily affected by the recommendations they get through external parties. This reflects a hazardous pattern that may put the health of children and young adults at risk through under achievement of basic nutritional requirements for a healthy life often by consuming excessive calories and intakes of fat, sugars etc. Food patterns of humans in the modern era are influenced by a variety of factors such as culture, values, economic status etc. and what stands out of all the above factors is the consumer loyalty towards certain brands that manufactures certain food and beverage products that may toxically affect the health and well being of children and adults (McGinnis, Gootman, \& Kraak, 2006).

Harris, Bargh, and Brownell (2009) states that researches on advertising to children has revealed that effective food advertising lead to greater product preference and often creates a purchasing behaviour among the minds of children and young adults. Food that are high in salts and sugars such as burgers, fries and soft drinks which are the core ingredients that lead to child obesity are heavily promoted in the mass media often as fast food combo meals by involving high creativity while the advertising of food that are not high in salts and sugars such as cereals, home cooked mixed meals are not so demanded by households for consumption (Jenkin, Wilson, \& Hermanson, 2009).

According to Samaraweera and Samanthi (2010) Food companies in Sri Lanka utilizes a number of modes such as television, radio, newspapers etc. to advertise their food and beverages to its consumers while television is considered to be the most effective advertising mode in the island mainly due to its heavy popularity as a mode of communication throughout the country where $86.3 \%$ TV penetration is recorded throughout the island higher than all other mass media networks available (Central Bank of Sri Lanka [CBSL], 2018). Thereby this study selected television media as the key mode of advertising to carry out the research and understand the advertising practices and effectiveness of the food industry in Sri Lanka.

The present study primarily focused on determining the impact of advertising effectiveness of healthy food and unhealthy food advertisements in Sri Lanka on consumer purchase intention as there is a lack of research on this area. This is new territory for public health in Sri Lanka and in South Asia. More research is needed to go forth with what other developed countries such as Sweden and Canada have achieved. Because of the paucity of information on food advertisements on television, there is an urgent need to evaluate food and beverages-related advertisements aimed at children and adults in Sri Lanka, which will not only help the Sri Lankan stake holders but all Asian countries (Prathapan, Wijewardena, \& Low, 2016).

\section{Literature Review}

Healthy food are the food that is accepted to be free of artificial chemicals and provide humans with the optimum amount of nutrients that are required to maintain a healthy and energetic lifestyle (Breastcancer.org, 2018; Cambridge Dictionary, 2020). High Contents of Salt, Sugar and Fat are the most common ingredients that are included in processed or unhealthy food and these ingredients make the foods more appealing and extending their shelf life thus making the people eating more than the recommended amount and making their way to deadly chronic illnesses (National Health Service UK, 2017).

The key reason for the use of advertising by corporates is to increase the profits of the advertiser. This can either be a short-term goal which is profits or a strategic long-term goal which is ideally 
building a strong brand, but no firm would invest money in advertising if positive returns are not expected. Generally advertising is carried in order to profit maximization by increasing sales but it may also contributed to profits in a way that by increasing the brand value or the cost of the brand associated with the company (Percy \& Rossiter, 1997).

Success in advertising is mainly related to the decision making in mission message, media, cost \& credit and result assessment of the campaign. Accordingly, success of an advertising campaign heavily depends on the precise selection and identification of the target audience, selection of ideal medium to advertise, right content creation of the advert with a clear message, the creative strategy used to carry out the campaign and the assessment of the advertising results respectively (Ghayoomi Javinani \& Shokri, 2014). Idris, Shukri, and Khatibi (2009) discusses that the effectivity of an advertisement depends on both the quality of the advertisement along with the quality of the product that is promoted aided by the context in media which the advertisement occurs.

Attracting Consumer Attention is the main goal behind the marketing of a certain product. The impact that is created through customer behaviour is mainly determined by multiple aspects, but the psychological-cognitive, emotional and behavioural aspects play the most significant roles (Jakštienè, Susnienè, \& Narbutas, 2008). Food Advertising is increasingly held responsible for encouraging masses for consumption of high calorie and fat unhealthy food products. These causes are directly linked to the obesity epidemic among both adults and children (Lobstein \& Dibb, 2005). Popular media houses in USA such as Discovery, Walt Disney and Nickelodeon has agreed to appear their merchandise only on healthy food items with high nutritional standards (Albiniak, 2007). It is identified that the modern consumers depend on food advertisements to retrieve nutritional information and the health benefits of the food they plan to consume (Chandra, Paul, \& Emmett, 2005).

Traditionally marketers have researched and found out that loyalty does effect in a positive word of mouth thus creating a positive purchase intention among consumers. According to Khuong, Hoa, and Nguyen (2016) customer loyalty is heavily affected by trust, brand recall and interest in relation to the brand. In a recent study carried out by Khuong et al. (2016) has found out that the more consumers are exposed to the advertisements by a particular brand, the more they will become loyal to that particular brand. Customer loyalty is built through frequently keeping up the associations with the customers mainly through effective advertising and understanding the customer needs and wants (Oliver, 1999).

Powerful food consumption signals are communicated through advertisements of Food and Beverages, these includes images of attractive models consuming snacks at non meal times along with lucrative emotions linked with consumption of Food (Folta, Goldberg, Economos, Bell, \& Meltzer, 2006; Harrison \& Marske, 2005). Chocolate, ice cream, cake, fruit juice and soft drinks that were advertised on mainstream media are mostly requested by preschool children and these desires were highly affected by mainstream media advertisements (Powell, Szczypka, Chaloupka, \& Braunschweig, 2007). It is also identified that majority of the food that are requested by children in supermarkets are the harmful food items which are high in fat and sugar content that are highly advertised on Television (Cezar, 2008).

\section{Methodology}

In order to carry out the research, non-random sampling method is adopted in which sample members are selected randomly. Under the non-random sampling technique, convenient sampling 
method is used in order to gather the first available primary data from a set of people that is easy to contact and reach. Since the population size of the research is 21.44 million, which is the population size of Sri Lanka, since it is more than one million, based on the Krejcie and Morgan sampling method research was conducted under a sample size of 384 members residing in the districts of Colombo, Gampaha and Anuradhapura. The key reason for selecting above 3 districts for the sampling purpose is the convenience the researchers associate with collecting data from the above districts as well as the population of the above 3 districts which represent a significant portion of the total population of Sri Lanka. In order to collect more accurate and precise data, the research used a selfadministrative questionnaire where the data is collected from participants by distributing it in both online and offline ways whichever convenient. The first part of the questionnaire mainly consists of the demographic factors namely age, sex while the remaining section is used to gather data in related to both healthy and unhealthy food advertising through the predesigned variables that ware designed to understand advertising effectiveness. Five-point Likert scale measurements were used to in the second segment of the questionnaire to understand how the predesigned variables affect the purchase intention ( $1=$ Strongly Disagree, 2=Disagree, $3=$ Neither Agree nor Disagree, $4=$ Agree, $5=$ Strongly Agree).

\section{Findings and Discussion}

The sample size of the study is 384 while the actual number of samples collected being 396 . Category of gender is represented by 230 and 166 male and female participants which is indicated as a percentage of $58.08 \%$ and $41.92 \%$ respectively. Under the category of age, majority of the sample is represented by respondents who are in between $22-37$ years of age which is 291 respondents, represented as a percentage of $73.48 \%$. The lowest participation is represented by the age above 54 years old which is 24 participants represented as $6.06 \%$ as a percentage. Usage of television is the third characteristic of demographic factors as the majority of the respondents of 319 participants which is $80.55 \%$ as a percentage stated that they watch television regularly while the remaining 77 participants which is $19.44 \%$ as a percentage stated vice-versa. The last demographic factor of the study which is the number of hours spent on watching television is largely dominated by 146 participants who stated that 1.-2 hours are spent daily to watch television which is $36.86 \%$ as a percentage while the least number of participants which is 53 stated that 4 hours a day is spent to watch television daily. 
INTERNATIONAL JOURNAL OF ACADEMIC RESEARCH IN BUSINESS AND SOCIAL SCIENCES Vol. 10, No. 5, May, 2020, E-ISSN: 2222-6990 @ 2020 HRMARS

Table 1: The Summary of Reliability and Validity

\begin{tabular}{|c|c|c|c|c|c|}
\hline & Variable & Question & Factor Loadings & $\mathrm{KMO}$ & Cronbach $\alpha$ \\
\hline \multirow{8}{*}{ 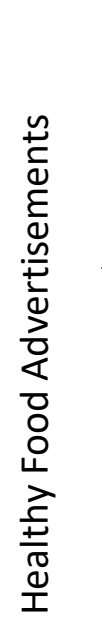 } & \multirow{4}{*}{ Loyalty } & LT1 & 0.789 & \multirow{4}{*}{0.810} & \multirow{4}{*}{0.9850} \\
\hline & & LT2 & 0.869 & & \\
\hline & & LT3 & 0.805 & & \\
\hline & & LT4 & 0.749 & & \\
\hline & \multirow[b]{4}{*}{ Purchase Intention } & PI 1 & 0.809 & \multirow[b]{4}{*}{0.807} & \multirow[b]{4}{*}{0.901} \\
\hline & & PI 2 & 0.880 & & \\
\hline & & PI 3 & 0.882 & & \\
\hline & & PI 4 & 0.789 & & \\
\hline \multirow{8}{*}{ 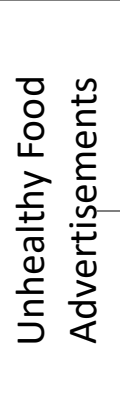 } & \multirow{4}{*}{ Loyalty } & LT1 & 0.786 & \multirow{4}{*}{0.768} & \multirow{4}{*}{0.921} \\
\hline & & LT2 & 0.884 & & \\
\hline & & LT3 & 0.840 & & \\
\hline & & LT4 & 0.776 & & \\
\hline & \multirow{4}{*}{ Purchase Intention } & PI 1 & 0.750 & \multirow[b]{4}{*}{0.846} & \multirow[b]{4}{*}{0.936} \\
\hline & & PI 2 & 0.795 & & \\
\hline & & PI 3 & 0.906 & & \\
\hline & & PI 4 & 0.890 & & \\
\hline
\end{tabular}

Table 1 represents the validity and the reliability of the data set that was considered before stepping into the further analysis. As per the table, majority of the factor loading values signifies a value greater than 0.7 hence it is concluded that majority of the factors has significantly contributed towards its distinct variables. Further, it can be concluded that all the variables have reached its required margins of $\mathrm{KMO}$ and Cronbach alpha values thus a strong validity and a reliability is evident in the data set.

Table 2: SEM Fitting Index

\begin{tabular}{cccc}
\hline Index of fit & Chi-sq./df & RMSEA & CFI \\
\hline Values & 3.450 & .079 & 0.900 \\
\hline
\end{tabular}

Table 2 represents the Model Fit Index of the study where three fitness indexes are used to study the fitness of the model. 
INTERNATIONAL JOURNAL OF ACADEMIC RESEARCH IN BUSINESS AND SOCIAL SCIENCES Vol. 10, No. 5, May, 2020, E-ISSN: 2222-6990 @ 2020 HRMARS

Table 3: Correlation between variables

r value $\quad P$-value

Healthy Food Advertisements

\begin{tabular}{llcc}
\hline LT1 & PI & 0.789 & 0.001 \\
\hline Unhealthy Food Advertisements & & \\
\hline LT2 & PI & 0.487 & 0.001 \\
\hline LT = Loyalty Value, PI = Purchase Intention & &
\end{tabular}

The above table illustrates the coefficient correlation between the Independent Variable which is Loyalty with the dependent variable of Purchase Intention in both Healthy and Unhealthy Food Advertisements. Loyalty factor in healthy food advertisements depicts a strong correlation with purchase intention with a $r$ Value of 0.789 at $\mathrm{P}<0.001$ significant points compared to that of the moderate correlation between loyalty of unhealthy food advertisements and purchase intention depicted by a $r$ Value of 0.487 at $\mathrm{P}<0.001$ significant points.

Table 4: Regression and hypothesis testing

\begin{tabular}{llll}
\hline \multicolumn{1}{l}{ Beta Value } & $\mathrm{P}$ - Value & Result \\
\hline Healthy Food Advertisements & & & \\
\hline LT1 & & & \\
\hline Unhealthy Food Advertisements & 0.106 & 0.001 & Supported \\
\hline LT2 $\longrightarrow$ PI & 0.177 & 0.001 & Supported \\
\hline LT = Loyalty Value, PI = Purchase Intention & & & \\
\hline
\end{tabular}

Table 4 represents the regression paths and hypothesis testing of the study's key two objectives. A comparative analysis of each objective, and the results are discussed based on the past findings and other relevant factors in order to come up with a clear idea on the concepts The First and the Second objective of the study focuses on studying the impact of Loyalty on Purchase Intention of both healthy and unhealthy food advertisements respectively, which is analysed lately as a comparison. At the end of the analysis the study found that Loyalty factor in healthy food advertisements depicts a strong correlation with purchase intention with a $r$ Value of 0.789 at $P<0.001$ significant points while the computation of impact of the above two variables found out a regression weight of $(\beta=0.122)$ at $P<0.001$. This indicates that when Loyalty Value of Healthy food advertisements increases by one unit, Purchase intention of healthy food advertisements increase by 0.106 units. In addition, (LT1 Loyalty Value of Healthy Food Advertisements creates a significant impact on PI) was found out to be statistically supported. On the other hand, loyalty factor in unhealthy food advertisements depicts a moderate correlation with purchase intention with a $r$ Value of 0.487 at $P<0.001$ significant points while the computation of impact of the above two variables found out a regression weight of $(\beta=0.177)$ at $P<0.001$. This indicates that when loyalty value of unhealthy food advertisements increases by one unit, Purchase intention of unhealthy food advertisements increase by 0.177 units. In addition, (LT2 - Loyalty Value of unhealthy food advertisements creates a significant impact on PI) was found out to be statistically supported. Belanche, Cenjor, and Pérez-Rueda (2019) and Hameed and Kanwal (2018) states that brand loyalty significantly affects the purchase intention of consumers and the key reasons for the above finding is that brand loyalty is often created through a positive experience a customer has had with the product previously. When it is looked into in the Sri Lankan context, through this study it is already found that, loyalty factor plays a huge role in purchase 
intention regardless of the health factor of the product. This is quite due to the positive experience that the customer has experienced with the product before. According to Kelly et al. (2010) some of the major food companies that produce unhealthy food products thrive due to the brand loyalty they have with regards to the products they produce. It is clearly evident that major food companies in the world produce some of the world's unhealthiest food and their brand names are almost invincible. On the other hand, as stated in the above study, some healthy food companies do thrive with regards to their brand loyalty as well. Thus it is clearly evident through this objective, customer loyalty is an invincible factor that any company lean to have and it is the same for food industry as well, rightly analyzed and depicted in the study, as Loyalty Value of both healthy and unhealthy food advertisements significantly affects the Purchase Intentions of Consumers.

\section{Conclusion}

The key objective of this study was to determine the affectivity of loyalty value in healthy and unhealthy food advertisements towards consumers' purchase intention. At the end of this study, comparable to many of the previous findings, it was evident that loyalty value in food advertisements creates a significant impact towards purchase intention regardless of the nature of the product. With regards to the Sri Lankan context of the current study it was found out that loyalty value in unhealthy food advertisements are highly effective compared to that of healthy food advertisements which is also found out be effective. Previous researchers has emphasized on the importance of loyalty factor in the food industry and with regards to the Sri Lankan scenario it is understood that the Sri Lankan healthy food manufacturers should emphasize more on developing consumer loyalty in their particular food and beverage brands so that they can effectively compete in the industry and carry out their marketing campaigns much more effectively compared to the unhealthy food manufacturers in Sri Lanka. Furthermore, higher the loyalty value in a particular food brand, higher the effectivity of the advertisement thus may help significantly in creating a purchase intention in the minds of the consumers.

The study is essentially significant for the emerging healthy food suppliers and manufacturers, entrepreneurs and the government of Sri Lanka. The study is greatly useful for the emerging healthy food suppliers and manufacturers to identify the impact of loyalty in advertising effectiveness on purchase intention of consumers. It will be beneficial for them to adapt the research findings into their advertising campaigns and commercials. The study encourages entrepreneurs to have new ways of thinking with regard to manufacturing and supplying of healthy food among Sri Lankan consumers. The study is similarly significant for the Sri Lankan government to impose stringent policies and regulations to control unhealthy food campaigns in Sri Lanka.

\section{References}

Albiniak, P. (2007). Nick, Discovery get healthy. Broadcasting and Cable, 137(33), 12.

Belanche, D., Cenjor, I., \& Pérez-Rueda, A. (2019). Instagram Stories versus Facebook Wall: an advertising effectiveness analysis.

Breastcancer.org. (2018). What does healthy eating mean? Retrieved from https://www.breastcancer.org/tips/nutrition/healthy_eat

Cambridge Dictionary. (2020). Health Food. Retrieved from https://dictionary.cambridge.org/dictionary/english/health-food 
INTERNATIONAL JOURNAL OF ACADEMIC RESEARCH IN BUSINESS AND SOCIAL SCIENCES

Vol. 10, No. 5, May, 2020, E-ISSN: 2222-6990 @ 2020 HRMARS

Central Bank of Sri Lanka [CBSL]. (2018). SRI LANKA SOCIO ECONOMIC DATA 2018. Retrieved from Colombo, Sri Lanka:

Cezar, A. (2008). The effects of television food advertising on childhood obesity. 5(1), 2.

Chandra, A., Paul, D., \& Emmett, D. (2005). An Exploratory Examination of Health Food Advertising: Consumer Perceptions, Behaviour and Acceptance. Journal of Medical Marketing, 5, 57-65. doi:10.1057/palgrave.jmm.5040202

Folta, S. C., Goldberg, J. P., Economos, C., Bell, R., \& Meltzer, R. (2006). Food advertising targeted at school-age children: A content analysis. Journal of Nutrition Education and Behavior, 38, 244248.

Javinani, G. M., \& Shokri, S. A. (2014). Role of Psychological Factors on Advertising Effectiveness. International Journal of Academic Research in Business and Social Sciences, 4. doi:10.6007/IJARBSS/v4-i10/1242

Hameed, S., \& Kanwal, M. (2018). Effect of Brand Loyalty on Purchase Intention in Cosmetics Industry. Research in Business and Management, 5, 25. doi:10.5296/rbm.v5i1.12704

Harris, J. L., Bargh, J. A., \& Brownell, K. D. (2009). Priming effects of television food advertising on eating behavior. 28(4), 404.

Harrison, K., \& Marske, A. (2005). Nutritional Content of Foods Advertised During the Television Programs Children Watch Most. American journal of public health, 95, 1568-1574. doi:10.2105/AJPH.2004.048058

Idris, I., Shukri, M., \& Khatibi, A. (2009). Personal and Psychological Factors-Does it Impact the Choice of Advertising Medium? Journal of Social Sciences, 5. doi:10.3844/jssp.2009.104.111

Jakštienè, S., Susnienè, D., \& Narbutas, V. (2008). The Psychological Impact of Advertising on the Customer Behavior. International Business Information Management Association (IBIMA), 3, 50-55.

Jenkin, G., Wilson, N., \& Hermanson, N. (2009). Identifying 'unhealthy' food advertising on television: a case study applying the UK Nutrient Profile model. Public Health Nutr, 12(5), 614-623. doi:10.1017/S1368980008003029

Kelly, B., Halford, J. C., Boyland, E. J., Chapman, K., Bautista-Castaño, I., Berg, C., . . Effertz, T. (2010). Television food advertising to children: a global perspective. 100(9), 1730-1736.

Khuong, M. N., Hoa, N. V., \& Nguyen, T. D. (2016). The Effect of Television Commercials on Customers' Loyalty - A Mediation Analysis of Brand Awareness. International Journal of Trade, Economics and Finance, 7(2).

Lobstein, T., \& Dibb, S. (2005). Evidence of a possible link between obesogenic food advertising and child overweight. 6(3), 203-208. doi:10.1111/j.1467-789X.2005.00191.x

McGinnis, J., Gootman, J., \& Kraak, V. (2006). Food marketing to children and youth: threat or opportunity?

Muiz, S. (2015). Harmful Food Advertising and alarming rise in NCDs. Retrieved from http://www.dailymirror.lk/96583/harmful-food-advertising-and-alarming-rise-in-ncds

National Health Service UK. (2017). Eating processed foods. Retrieved from https://www.nhs.uk/livewell/eat-well/what-are-processed-foods/

Oliver, R. L. (1999). Whence Consumer Loyalty? Journal of Marketing, 63, 33-44.

Percy, L., \& Rossiter, J. R. (1997). Advertising communications and promotion management: McGrawHill. 
INTERNATIONAL JOURNAL OF ACADEMIC RESEARCH IN BUSINESS AND SOCIAL SCIENCES

Vol. 10, No. 5, May, 2020, E-ISSN: 2222-6990 @ 2020 HRMARS

Powell, L. M., Szczypka, G., Chaloupka, F. J., \& Braunschweig, C. L. (2007). Nutritional Content of Television Food Advertisements Seen by Children and Adolescents in the United States. 120(3), 576-583. doi:10.1542/peds.2006-3595 \%J Pediatrics

Prathapan, S., Wijewardena, K., \& Low, W. Y. (2016). Content Analysis of Food and Beverages Advertisements Targeting Children and Adults on Television in Sri Lanka. 28(1_suppl), 86S92S. doi:10.1177/1010539515620481

Samaraweera, G., \& Samanthi, K. (2010). Television advertising and food demand of children in Sri Lanka: a case study from Galle District. 